\title{
Caregivers Knowledge, Attitude and Practices on Child Growth Monitoring and Promotion Activities in Lawra District, Upper West Region of Ghana
}

\author{
Debora Tuobom Debuo", Prince Kubi Appiah", ", Margaret Kweku², Geoffrey Adebayo Asalu ${ }^{1}$, \\ Seth Yao Ahiabor ${ }^{2}$, Wisdom Kwami Takramah ${ }^{2}$, Abdulai Bonchel Duut ${ }^{3}$ \\ ${ }^{1}$ Department of Family and Community Health, School of Public Health, University of Health and Allied Sciences, Ho, Ghana \\ ${ }^{2}$ Department of Epidemiology and Biostatistics, School of Public Health, University of Health and Allied Sciences, Ho, Ghana \\ ${ }^{3}$ Department of Social Work, University of Ghana, Legon, Accra, Ghana
}

Email address:

appiahkubiprince23@yahoo.com (P. K. Appiah)

${ }^{*}$ Corresponding author

\section{To cite this article:}

Debora Tuobom Debuo, Prince Kubi Appiah, Margaret Kweku, Geoffrey Adebayo Asalu, Seth Yao Ahiabor, Wisdom Kwami Takramah, Abdulai Bonchel Duut. Caregivers Knowledge, Attitude and Practices on Child Growth Monitoring and Promotion Activities in Lawra District, Upper West Region of Ghana. Science Journal of Public Health. Vol. 5, No. 1, 2017, pp. 20-30. doi: 10.11648/j.sjph.20170501.13

Received: November 17, 2016; Accepted: December 5, 2016; Published: January 4, 2017

\begin{abstract}
Background: Growth monitoring and promotion (GMP) activities serve as an important platform for the implementation of child survival interventions to reduce malnutrition, infectious diseases and death among children. In recent times, there has been a steady decline in GMP outcome indicators in the Lawra district. The appropriate practices of GMP help in improving knowledge, attitudes and practices of caregivers towards child nutrition and health. Therefore, this study seeks to assess knowledge, attitude and practices of growth monitoring and promotion and associated factors among caregivers. Methods: A descriptive cross-sectional study design was used to study 300 caregivers'. Multi-stage sampling technique was used to select the participants. A semi-structured questionnaire applying face to face interview approach was used to collect data from participants. Descriptive statistics and associations between dependent and independent variables were done using Pearson chi-square and logistic regression analysis. Results: The results indicated 53\% of the caregivers' with good (high) knowledge in Growth Monitoring and Promotion (GMP) activities, 98\% with good (high) attitudes towards GMP activities and $70 \%$ with good (high) practices in GMP. Also, 16.2\% of caregivers' children had faltered in growth. Occupation was associated with knowledge $(p=.013)$, and attitude $(p=.014)$. Again, educational status $(p=.026)$ was associated with knowledge in GMP, marital status $(p=.009)$ and child relation with caregiver $(p=.021)$ were associated with attitude in GMP. Also tribe $(p=.019)$ and child relation with caregiver $(p=.019)$ were significantly associated with practices in GMP. Conclusions: Notwithstanding the achievement in the coverage of GMP, implementation of Infant and Young Child Feeding (IYCF) program and Information, Education and Communication (IE\&C) activities in district, the findings on GMP outcome (knowledge and practice) is not satisfactorily. District Health Directorate need to intensify and strengthen IYCF activities, home visits, health education, and growth monitoring and promotion services.
\end{abstract}

Keywords: Knowledge, Attitude, Practice, Growth Monitoring and Promotion, Caregiver

\section{Introduction}

Growth monitoring and promotion (GMP) is a session organized in a community or at a health facility where preventive services and promotional services are implemented to improve and maintain child health and nutrition, and also linked the activity to other services like family planning and ante-natal services [1]. They further explained that growth monitoring is a preventive activity with a focus on systematic monitoring of a child growth through anthropometric measurement over a period of time, weight recording, plotting and growth curved interpretation as normal or abnormal in comparison with WHO growth Z- 
scores to detect growth failures early for appropriate measures. On the other hand, the promotional activity aspect relies on the growth pattern of the child to be used by the health worker and caregivers' to determine appropriate actions to promote growth in children. These actions includes counselling individual child according to their needs and their growth pattern, treatment services or further medical investigation or referral to higher levels to manage their conditions and finally follow up visits to ensure that growth faltering causes are being addressed at home [2].

The processes involved in growth monitoring and promotion as a component of community nutrition programs include but not limited to assessment like weighing, plotting and interpretation of growth curve, analysis like determination of normal and abnormal growth and action such as motivation, education and counselling, treatment, referral and home visits [1\&3]. Growth monitoring and promotion is also expected to achieve the following results; increase adequate diet intake in children, improve child care practices among caregivers, increase need for health care services among caregivers, improve infection prevention and control diseases [2\&4]. It also helps in reducing child morbidity and mortality by using it as a contact points for other programs for child survival, growth and development [5-6].

Though growth monitoring and promotion present a brighter future for our children, there are issues surrounding its practices. A descriptive qualitative study carried out in Ethiopia indicated that there was low maternal knowledge on feeding practices and low participation of husbands in a child growth monitoring and promotion activities [6]. Also, a cross-sectional study conducted in Ghana, pointed out that about $50 \%$ of the children weighed at the GMP sessions weights were not properly plotted in their child health record cards, and about $60 \%$ of caregivers interviewed had no promotional counselling during their attendance [7]. Another discrepancy is the fact that Growth monitoring and promotion coverage is high $(95.3 \%)$ nationally, but the district has shown a decline in the coverage from $2012-2014$ with $82.9 \%, 78.2 \%$ and $72.2 \%$ respectively [8].

Furthermore, in Zambia, a prospective study showed that GMP programs have performed poorly due to weak monitoring and supervision, poor practices among health workers and the lack of motivational package attached to the program [9]. This study therefore seeks to assess the knowledge, attitude and practices of growth monitoring and promotion among caregivers in Lawra District of Upper West Region, Ghana.

\section{Materials and Methods}

\subsection{Study Site}

The study was carried out in the Lawra district of the Upper West Region of Ghana. The district is one of the eleven (11) administrative districts in the region. It is located in the north western part of the region; shares boundaries with Nandom district to the north, eastern with Jirapa, south west with the Black Volta and Burkina Faso. It has total land area of 527.37 square kilometres, with a population density of 104.1 people. The projected population of the district is 59,131 people based on the 2010 population and housing census with a growth rate of about $1.5 \%$. The district lies within the Savanna zone characterized by dry hot weather with short grass and some typical trees such as Baobab, Dawadawa and shea nut. Majority of inhabitants $(80 \%)$ are rural dwellers, and has been estimated that $82.4 \%$ of the population are engaged in subsistence farming, 79\% were economic productive. In addition, $45.3 \%$ of the population are literate.

The district has a hospital, a polyclinic, four (4) health centres, eleven (11) community health planning and service compound (CHPS) and one (1) Christian Health Association of Ghana (CHAG) facility. Growth monitoring and promotion services are rendered at facility-based (static) and outreach clinics in the communities. A total of 78 sessions are run monthly to assess the growth of children 0-59 months in the district. Other services provided at the sessions include immunization, vitamin A supplementation, health education and counselling, screening for nutritional and medical conditions for management, defaulter tracing and follow-ups.

\subsection{Study Population}

The study participants were caregivers' with children 0 23 months who have registered and were attending GMP session in the district. Only those who were willing to be part of the study and to sign the consent forms were included in the study. Also, those who have not stayed in the district for one or more years were excluded, as well as Non-Ghanaians and Health professionals even if they have stayed in the municipality for the required period.

\subsection{Study Design}

The study was descriptive cross-sectional conducted between February and April, 2016, and it assessed knowledge, attitude and practices of growth monitoring and promotion and associated factors among caregivers in the district.

\subsection{Sample Size}

The sample size was 300 and was determined using the formula: $n=z^{2} * p(q) \div d^{2}[10]$, Where $n$ is the Sample size to be determined, $\mathrm{z}$ is the $\mathrm{z}$-score (reliability coefficient) of 1.96 at $95 \%$ confidence level (C. L), p is the estimated proportion of an attribute that was present in the population (prevalence of underweight 0.135 ) [8], and $d$ is the desired level of precision $5 \%(0.05)$, and $\mathrm{q}$ is $1-\mathrm{p}$. With the extra uncertainty about the true outcome of GMP due to the cluster sample survey design, design effect was considered in the sample size calculation. Therefore, the sample size became $n^{*}$ design effect (which was 1.5 in this case). For a $10 \%$ non-response rate of 270 , the sample size was upwardly adjusted and rounded to 300 participants. This sample size ensured, with probability of $95 \%$ that, the estimated prevalence fell within $\pm 5 \%$ of the true population level. 


\subsection{Sampling Method}

Multi-stage sampling method was used to select the caregivers. The district was stratified into five (5) strata. A list and attendance of all outreach sites in each stratum was obtained from the District Health Directorate. A sample size was proportionately allocated to each stratum based on the number of children between 0-23 months attending growth monitoring and promotion. For each stratum, three (3) outreach sites were randomly selected. Based on the sample size calculated for each stratum and the population of children (0-23months) attending growth monitoring and promotion at each outreach site, proportionate allocation was used to select the number of children for each outreach site. In each outreach site, caregivers' with children within 023months were identified and selected through balloting (YES or NO) to collect the data for the study. A caregiver who picks YES was interviewed.

\subsection{Data Collection}

A semi-structured questionnaire, pen, paper and growth chart was used to obtained data on knowledge, attitude and practice on GMP from participants as well as other background information of the respondents using face to face interview technique. In order to ensure standard and comparison of results, questionnaire were adopted and adjusted from the C-IYCF key message booklet in Ghana and indicators for IYCF practices.

Participants' ages were assessed using their Birth Certificates. Where certificates were not available, events calendar were used to determine their age.

\subsection{Ethical Issues}

Participation in the study conformed to the required ethical guidelines regarding the use of human subjects. The study approved by the Ethical Review Committee of the Ghana Health Services, Research and Development Division, Accra with protocol number GHS-ERC 03/02/16. Participation in the study was voluntary, and consent was sought from the women.

\subsection{Data Analysis}

Data was entered using EPI data version 2.1b Software and then exported Stata version 11 (StatCorp, college Station, Texas, USA) for analysis. Data cleaning and validation was done to ensure data quality before analysis was carried out. Descriptive statistics including mean and standard deviation was calculated for quantitative variables whilst proportions and percentages was calculated for categorical variables and presented in graphs. Beyond descriptive statistics, Chi-square test was used to examine the association between knowledge, attitudes and practices and each of the background characteristics. Logistic regression was used to identify the strength of possible factors (independent variables) associated with the dependent variable (Knowledge, attitude and practices). A p-value $<0.05$ was considered as statistically significant.

Correct responses were scored with one (1) point whilst a zero (0) point for wrong and don't know responses for knowledge, attitude and practice

Knowledge was assessed based on 12 scores: Participants who scored 0-4 points were considered of having low knowledge in GMP activities; those who scored 5-8 point were also considered to have moderate knowledge in GMP activities while those who scored 9-12 points were classified as having high knowledge in GMP.

Attitude was measured based on 11 scores: Participants who scored 0-3 points were considered having low attitude towards GMP activities; those who scored 4-7 point were also considered to have moderate attitude towards GMP activities while those who scored 8-11 points were classified as having high attitude towards GMP.

Practices were considered based on 3 scores: Participants who scored 1 point were considered having low practices in GMP; those who scored 2 points were also considered to have moderate practices in GMP while those who scored 3 points were classified as having high practice in GMP.

\section{Results}

\subsection{Background Characteristics of Caregivers'}

Table 1. Background characteristics of caregivers.

\begin{tabular}{|c|c|c|}
\hline Attribute & & Number (\%) \\
\hline \multirow{3}{*}{ Child's Age } & $0-5$ & $75(25.0)$ \\
\hline & $6-11$ & $82(27.3)$ \\
\hline & $12-23$ & $143(47.7)$ \\
\hline \multirow{2}{*}{ Childs'sex } & Male & $144(48.0)$ \\
\hline & Female & $156(52.0)$ \\
\hline \multirow{4}{*}{ Birth weight (kg) } & No birth weight & $47(15.7)$ \\
\hline & Less than 2.5 & $31(10.3)$ \\
\hline & Between 2.5-4.0 & $220(73.3)$ \\
\hline & Above 4.0 & $2(0.7)$ \\
\hline \multirow{3}{*}{ Caregiver Age } & $15-25$ & $82(27.3)$ \\
\hline & $26-35$ & $161(53.7)$ \\
\hline & $46-65$ & $57(19.0)$ \\
\hline \multirow{2}{*}{ Sex of caregiver } & Male & $0(0.0)$ \\
\hline & Female & $300(100.0)$ \\
\hline \multirow{3}{*}{ Caregiver relation with child } & Mother & $289(96.3)$ \\
\hline & Grand mother & $10(3.3)$ \\
\hline & Stepmother & $1(0.4)$ \\
\hline \multirow{4}{*}{ Marital status } & Married & $271(90.3)$ \\
\hline & Divorced & $2(0.6)$ \\
\hline & Widower & $10(3.3)$ \\
\hline & Single & $17(5.6)$ \\
\hline \multirow{2}{*}{ Type of marriage } & Monogamous & 249 (91.9) \\
\hline & Polygynous & $22(8.1)$ \\
\hline \multirow{4}{*}{ Occupation } & Farmer/livestock & $175(58.3)$ \\
\hline & Trader & $80(26.6)$ \\
\hline & Formal & $13(4.3)$ \\
\hline & *Others & $32(10.6)$ \\
\hline \multirow{6}{*}{ Educational level } & No education & $158(52.6)$ \\
\hline & Primary & $43(15.3)$ \\
\hline & Middle school & $2(0.6)$ \\
\hline & JHS & $59(19.6)$ \\
\hline & SHS/Technical & $20(6.6)$ \\
\hline & Tertiary & $15(5.0)$ \\
\hline \multirow{4}{*}{ Religion } & Christianity & $232(77.3)$ \\
\hline & Islam & $14(4.6)$ \\
\hline & Traditional & $47(15.6)$ \\
\hline & Pagans & $7(2.3)$ \\
\hline
\end{tabular}




\begin{tabular}{lll}
\hline Attribute & & Number (\%) \\
\hline \multirow{3}{*}{ Tribe } & Dagaabas & $289(96.3)$ \\
& Waalas & $5(1.6)$ \\
& $* *$ Others & $6(2.0)$ \\
\hline
\end{tabular}

*Includes housewife, artisans and students.

**Includes Hausas and Akans.

Means and standard deviations; age of caregivers' $29.7 \mathrm{yrs} \pm 7.29$, age of children $11.1 \mathrm{mths} \pm 6.37$ and Birth weight of children $2.5 \mathrm{~kg} \pm 0.75$

A total of 300 caregivers were interviewed and about $96.3 \%$ of them were biological mothers of the children; as low as $9.7 \%$ of the caregivers were not married, and most $(83.0 \%)$ of caregivers' were in monogamous marriage. Over $58.3 \%$ of the caregivers were farmers with the least being formal work (4.3\%). Majority (52.6\%) have not been educated, and only (5\%) of them had completed tertiary education. More than half $(52.0 \%)$ of the children in this study were females. More than half $(75.0 \%)$ of the children were above six (6) months. Majority (96.3\%) of the caregivers were 'Dagaabas', whereas $1.6 \%$ and $2.0 \%$ were 'Waalas' and others respectively. About $77.3 \%$ of them were Christians (Table 1).

\subsection{Caregivers Knowledge in Growth Monitoring and Promotion}

About $70.3 \%$ of the caregivers expressed the meaning of GMP to be weighing whilst $26.7 \%$ related it as immunization/treatment of ailments. Some $52.7 \%$ of the caregivers associated the importance of GMP to improve child care practices, and others also related it to acquire knowledge on child care (39\%) (Table 2).

Table 2. Caregivers knowledge in growth monitoring and promotion.

\begin{tabular}{|c|c|c|}
\hline Knowledge indicators & Responses & Number (\%) \\
\hline \multirow{4}{*}{ Meaning of GMP } & Weighing & $211(70.3)$ \\
\hline & Immunization & $56(18.7)$ \\
\hline & Treatment of ailment & $24(8.0)$ \\
\hline & Don't Know & $9(3.0)$ \\
\hline \multirow{3}{*}{ Importance of GMP } & Acquire knowledge on care practices & $117(39.0)$ \\
\hline & Improve on child care practices & $158(52.7)$ \\
\hline & Don't know & $25(8.3)$ \\
\hline \multirow{3}{*}{ Frequency of attendance in GMP } & Once a month & $286(95.3)$ \\
\hline & Twice in a quarter & $2(0.7)$ \\
\hline & Don’t know & $12(4.0)$ \\
\hline \multirow{2}{*}{ Purpose of growth chart } & Monitor growth & $236(78.7)$ \\
\hline & Don’t know & $64(21.3)$ \\
\hline \multirow{2}{*}{ Initiation of breast milk } & At Birth & $291(97.0)$ \\
\hline & Don't know & $9(3.0)$ \\
\hline \multirow{3}{*}{ Introduction of complementary feeds } & At 6 months & $263(87.7)$ \\
\hline & After 6months & $12(4.0)$ \\
\hline & Don't know & $25(8.3)$ \\
\hline \multirow{2}{*}{ Required feeding frequency (0-6 months) } & On demand & $253(84.3)$ \\
\hline & Don't know & $47(15.7)$ \\
\hline \multirow{3}{*}{ Required feeding frequency (6-11 months) } & $\geq 3$ times & $257(85.7)$ \\
\hline & $<3$ times & $19(6.3)$ \\
\hline & Don't know & $24(8.0)$ \\
\hline \multirow{3}{*}{ Required feeding frequency (12-23 months) } & $\geq 4$ times & $160(53.3)$ \\
\hline & $<4$ times & $109(36.3)$ \\
\hline & Don't know & $31(10.4)$ \\
\hline
\end{tabular}

Only $56(18.7 \%)$ of the caregivers were able to interpret all the four growth curves (normal, static, decline and upward growth curves) (Figure 1). Just 102 (34\%) of the caregivers' were able to interpret a static curve appropriately.

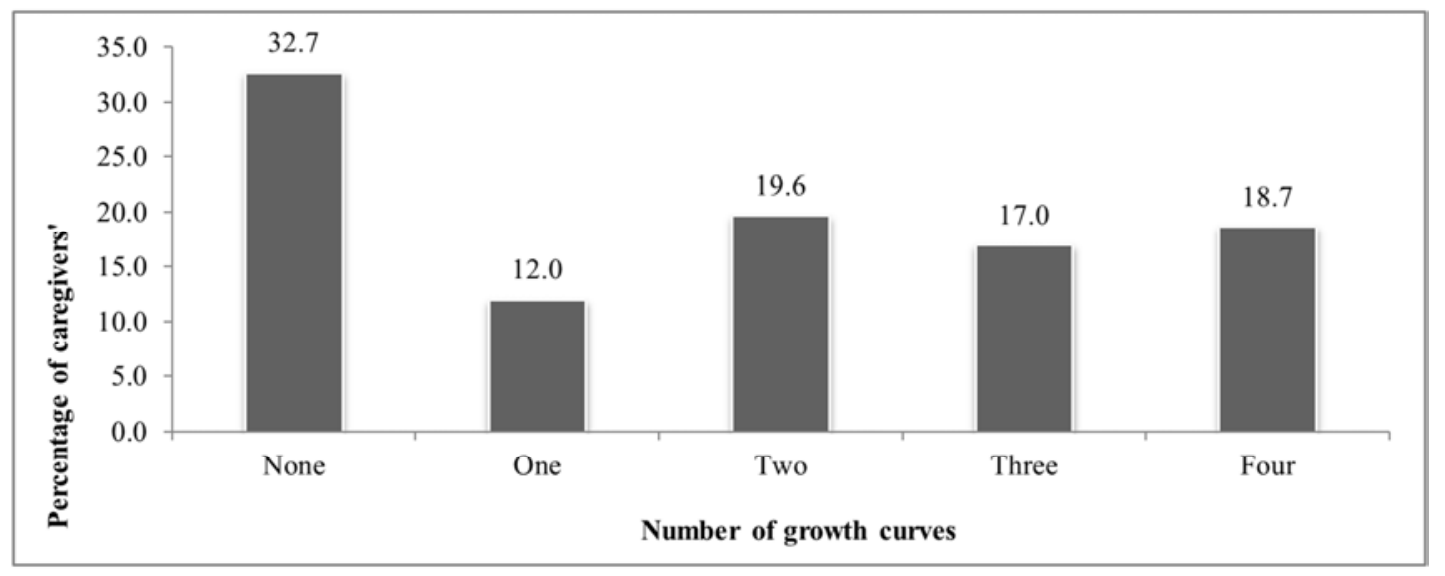

Figure 1. Percentage of caregivers' comprehension on growth curves. 
Just $159(53 \%)$ of the caregivers had high knowledge in GMP (figure 2).

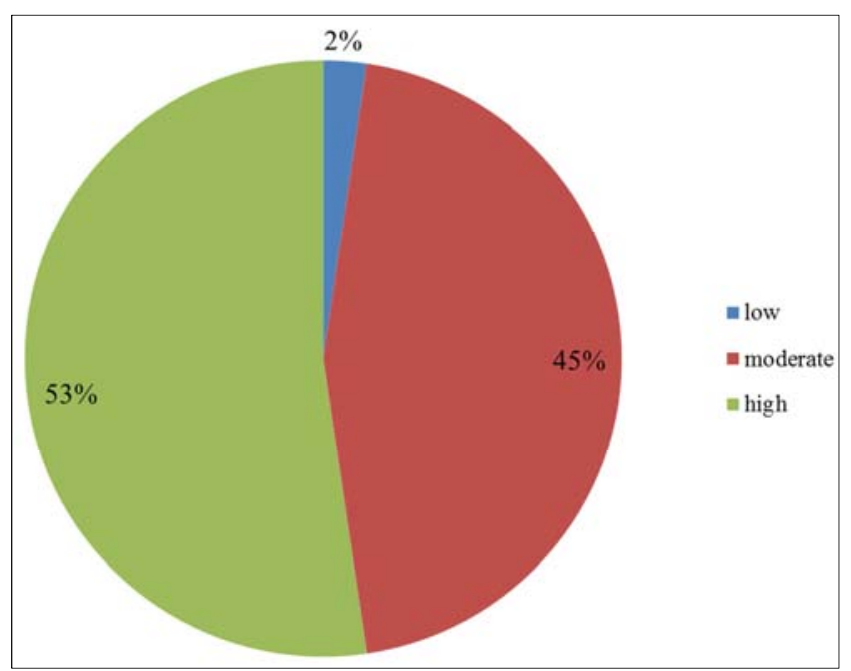

Figure 2. Caregivers knowledge in growth monitoring and promotion.

\subsection{Caregivers Attitudes Toward Growth Monitoring and Promotion}

Majority (93.7\%) of the caregivers' had good perception to attend growth monitoring and promotion session. Though, perception about attending GMP session was high among caregivers, as high as $10.7 \%, 11.6 \%, 7.3 \%$ and $4.0 \%$ have poor perception on practices such as exclusive breastfeeding, complementary feeding, hand washing and health care seeking respectively (Table 3 ).

About $84.0 \%$ of the caregivers' have good reasons perceived in attending GMP session. However, more than one-third of the caregivers had bad reasons for their perceived attitudes towards exclusive breastfeeding, complementary feeding, hand washing and seeking early health care (Table 4).

Table 3. Caregivers' attitudes toward growth monitoring and promotion.

\begin{tabular}{lll}
\hline Attributes & Responses & Number (\%) \\
\hline \multirow{3}{*}{ Feelings about attending GMP } & Good & $281(93.7)$ \\
& Not sure & $10(3.3)$ \\
& Bad & $9(3.0)$ \\
Exclusive Breastfeeding & Not difficult & $67(89.3)$ \\
& Not sure & $0(0.0)$ \\
& Difficult & $8(10.7)$ \\
Complementary feeding & Not difficult & $199(88.4)$ \\
& Not sure & $9(4.0)$ \\
& Difficult & $17(7.6)$ \\
Hand washing & Not difficult & $278(92.7)$ \\
& Not sure & $20(6.7)$ \\
& Difficult & $2(0.6)$ \\
Seeking early health care & Not difficult & $288(96.0)$ \\
& Not sure & $6(2.0)$ \\
& Difficult & $6(2.0)$ \\
\hline
\end{tabular}

Table 4. Reasons of caregivers'attitudes in GMP.

\begin{tabular}{lll}
\hline Attributes & & Number (\%) \\
\hline \multirow{2}{*}{ Attendance in GMP } & Good reasons & $252(84.0)$ \\
& Bad reasons & $48(16.0)$ \\
Exclusive breastfeeding & Good reasons & $49(65.3)$ \\
& Bad reasons & $26(34.7)$ \\
Complementary feeding & Good reasons & $136(60.4)$ \\
& Bad reasons & $89(39.6)$ \\
Hand washing & Good reasons & $192(64.0)$ \\
& Bad reasons & $108(36.0)$ \\
Seeking early healthcare & Good reasons & $209(69.7)$ \\
& Bad reasons & $91(30.3)$ \\
\hline
\end{tabular}

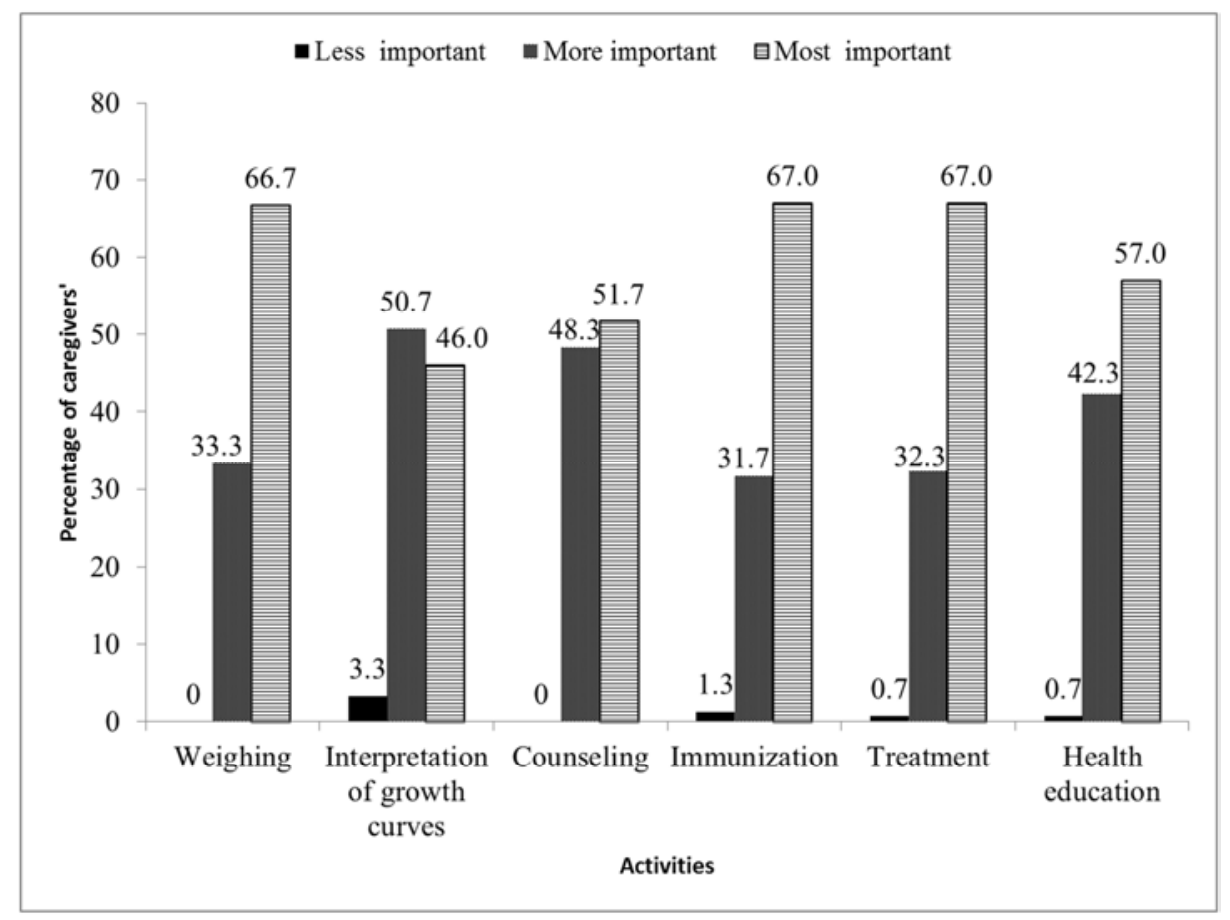

Figure 3. Caregivers preference of activities of importance in GMP. 
As many as $201(67.0 \%)$ of caregivers preferred: weighing, immunization and treatment of ailments respectively as most important perceived activities in the GMP session. However, few caregivers felt these activities were less important which includes interpretation of graphs $10(3.3 \%)$, immunization $4(1.3 \%)$, and treatment of ailment $2(0.7 \%)$ and health education $2(0.7 \%)$ (Figure 3$)$.

About $50.0 \%$ of caregivers stated that interpretation of graph was less important to them because it was not done in respect to their child's growth curves. Also in immunization $(42.8 \%)$ caregivers said that their children cry after the vaccination (Table 5).

Table 5. Reasons of GMP activity as less important by caregivers.

\begin{tabular}{lll}
\hline Attributes & Reasons & Number (\%) \\
\hline & Interpretation of graph is not done & $4(50.0)$ \\
Interpretation & Nurses ask me questions & $1(12.5)$ \\
of growth & Delays process & $1(12.5)$ \\
curve & No reason & $1(12.5)$ \\
& Lacks understanding of what it mean & $1(12.5)$ \\
& Makes the child to cry & $3(42.9)$ \\
Immunization & Child had fever & $1(14.3)$ \\
& No reason & $3(42.9)$ \\
Treatment of & Treatment is not done at session, but & $2(50.0)$ \\
ailment & referred to the clinic & $2(50.0)$ \\
Health & No reason & $1(100)$ \\
education & Delays me for other activities & \\
\hline
\end{tabular}

About 294 (98.0\%) of the caregivers had perceived high attitudes toward growth monitoring and promotion (Figure 4).

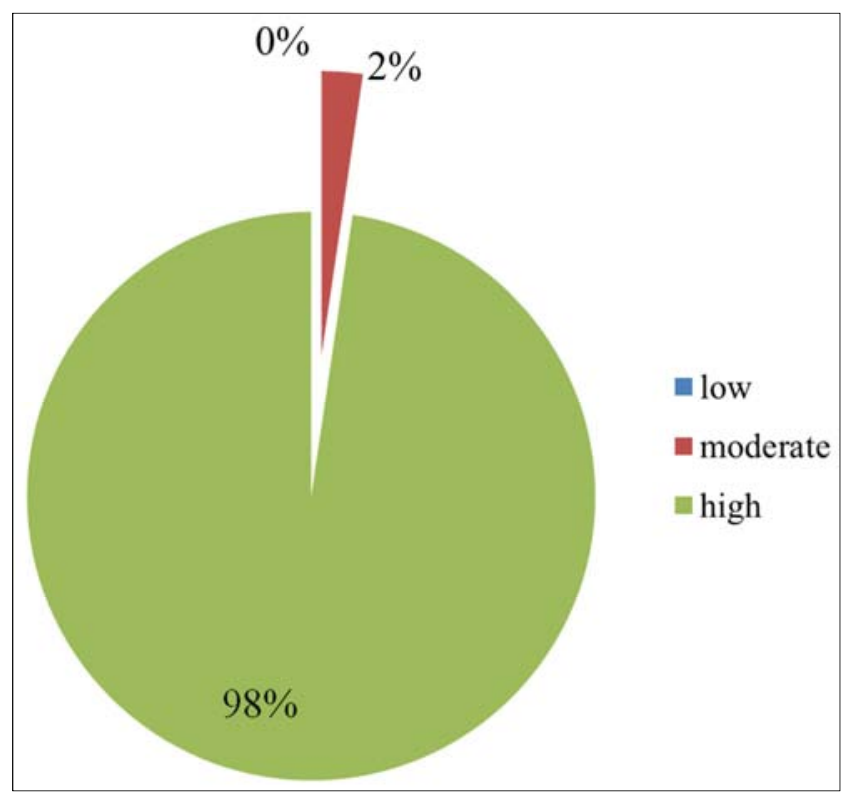

Figure 4. Caregivers attitudes toward growth monitoring and promotion.

\subsection{Practices of Caregivers in Growth Monitoring and Promotion}

Majority $(88.0 \%)$ of the caregivers' with children $<6$ months were practicing exclusive breastfeeding. As high as $47.6 \%$ of the caregivers' with children $\geq 6$ months were not feeding their children with diverse diet. In addition, on hand washing almost all $(99.7 \%)$ of these caregivers' had washed their hands in the previous day. However, $27.1 \%$ did wash their hands after visiting toilet. More than half $(63.9 \%)$ of the caregivers' used their ITN the previous night (Table 6).

Table 6. Caregivers practices on recommended child care practices for $24 \mathrm{hr}$ recall.

\begin{tabular}{|c|c|c|}
\hline Feeding practices & Responses & Number (\%) \\
\hline Practicing Exclusive & Yes & $67(88.0)$ \\
\hline Breastfeeding & No & $8(12.0)$ \\
\hline \multirow{2}{*}{ Continuous Breastfeeding } & Breastfed & $215(95.6)$ \\
\hline & Did not breastfed & $10(4.4)$ \\
\hline \multirow[t]{2}{*}{ *Frequency of feeding } & $\begin{array}{l}\text { Recommended frequency } \\
\text { of diet }\end{array}$ & $192(85.3)$ \\
\hline & Not as recommended & $33(14.7)$ \\
\hline \multirow{2}{*}{$\begin{array}{l}* * \text { Variety of foods } \\
\text { consumed }\end{array}$} & Recommended diverse diet & $118(52.4)$ \\
\hline & Not as recommended & $107(47.6)$ \\
\hline \multirow{2}{*}{ Hand washing } & Yes & $299(99.7)$ \\
\hline & No & $1(0.3)$ \\
\hline \multirow{2}{*}{ After visiting the toilet } & Yes & $218(72.9)$ \\
\hline & No & $81(27.1)$ \\
\hline \multirow{2}{*}{ Before cooking } & Yes & $203(67.9)$ \\
\hline & No & $96(32.1)$ \\
\hline \multirow{2}{*}{$\begin{array}{l}\text { Before eating and feeding } \\
\text { the child }\end{array}$} & Yes & $239(79.9)$ \\
\hline & No & $60(20.1)$ \\
\hline \multirow{2}{*}{ After eating food } & Yes & $169(56.5)$ \\
\hline & No & $130(43.5)$ \\
\hline \multirow{2}{*}{ Ownership of ITNs } & Yes & $266(88.7)$ \\
\hline & No & $34(11.3)$ \\
\hline \multirow{5}{*}{$\begin{array}{l}\text { The last time child slept } \\
\text { under ITN }\end{array}$} & Last night & $170(63.9)$ \\
\hline & A week ago & $47(17.7)$ \\
\hline & Two weeks ago & $29(10.9)$ \\
\hline & One month ago & $10(3.8)$ \\
\hline & Others & $10(3.8)$ \\
\hline
\end{tabular}

* Minimum meal frequency of 2 for (6-8months) \& 3 for $6-23$ months as recommended (C-IYCF key message booklet in Ghana)

${ }^{* *}$ Minimum of 4 food variety was used for 6-23month as recommended (C-

IYCF key message booklet in Ghana)

Most $210(70.0 \%)$ of the caregivers' had moderate practices in GMP with only $75(25.0 \%)$ of caregivers having good practice in GMP (Figure 5).

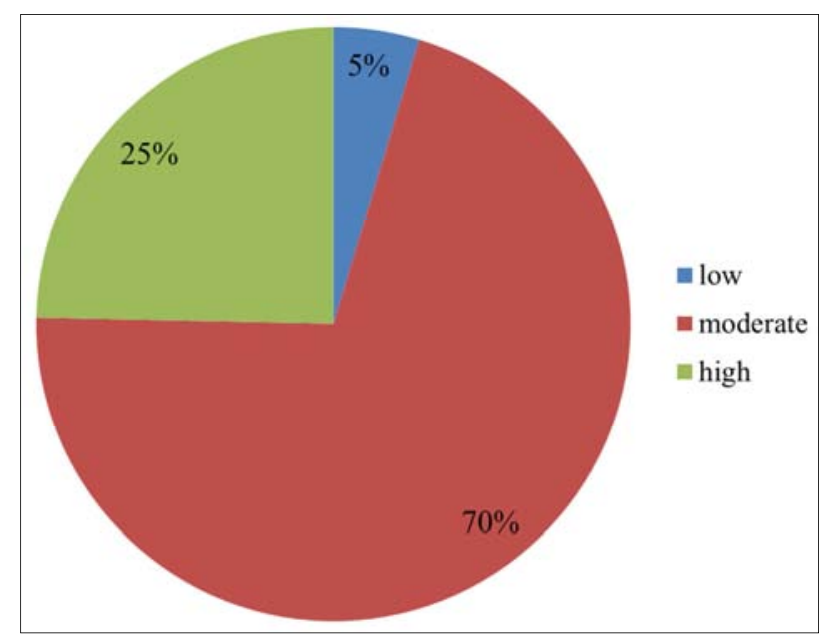

Figure 5. Caregivers practices in growth monitoring and promotion. 


\subsection{Growth Faltering Among Caregivers' Children in GMP}

Table 7. Distribution of growth pattern and recommendations among caregivers.

\begin{tabular}{lll}
\hline Attributes & & Number (\%) \\
\hline \multirow{2}{*}{ Recording in weight } & Plotted & $197(66.0)$ \\
& Not plotted & $103(34.0)$ \\
Growth pattern & Faltering & $32(16.2)$ \\
& No faltering & $165(83.8)$ \\
Duration of growth faltering & One month & $23(71.9)$ \\
& Two month & $9(28.1)$ \\
& Decline & $17(53.1)$ \\
Type of growth pattern & Sharp upward & $1(3.1)$ \\
& Static & $14(43.8)$ \\
Growth faltering & $0-5$ months & $5(15.6)$ \\
& 6-11months & $7(21.9)$ \\
Recommendations for & 12-23months & $20(62.5)$ \\
caregivers' & Received & $192(64.0)$ \\
& Not received & $108(36.0)$ \\
& Referral for screening & $10(5.1)$ \\
Type recommended actions & and treatment & $0(0.0)$ \\
& Home visit & $1(0.5)$ \\
& CMAM & $186(94.4)$ \\
\hline
\end{tabular}

As high as $34.0 \%$ of the children weights were not recorded and plotted in the growth charts. However, out of the 197 children whose weights were plotted, $16.2 \%$ of them had faltered growth for the past two (2) months preceding the study. About $71.9 \%$ of the caregivers' children had their growth faltering within one (1) month, more than half (53.1\%) of these children growth declined. Though most (94.4\%) caregivers' were encouraged to continue good practices, just $5.6 \%$ of these children were referred for further screening and treatment/CMAM this indicates that some caregivers' children with faltered growth were still encouraged (Table 7).

\subsection{Associations Between the Background Characteristics and Caregivers Knowledge in GMP Activities}

There was significant associations between knowledge in GMP and occupation ( $p=.013)$ and educational status $(p=.026)$. To further examine the strength of associations, multiple logistic regression analysis was used to confirm associations between knowledge in GMP and the independent variables. The analysis did confirm the associations between knowledge in GMP and educational status. The associations also indicated that caregivers with no education were $39.0 \%$ less likely to be associated with good knowledge in GMP than educated caregivers, also caregivers with informal occupation were $85.0 \%$ less likely to be associated with good knowledge in GMP than those with formal occupation,. Furthermore, when variables that were having associations with good knowledge in GMP from bivariate analysis were explored for strength of associations, it confirmed that there was no association (Table 8).

Table 8. Associations between the background characteristics and caregivers knowledge in GPM.

\begin{tabular}{|c|c|c|c|c|c|c|}
\hline \multirow{2}{*}{$\begin{array}{l}\text { Background } \\
\text { Characteristics }\end{array}$} & \multicolumn{2}{|c|}{ Knowledge in GMP } & \multicolumn{2}{|c|}{ Pearson chi square } & \multicolumn{2}{|c|}{ Odd ratio/Confidence Interval } \\
\hline & $\begin{array}{l}\text { Good (high) n } \\
(\%)\end{array}$ & $\begin{array}{l}\text { Poor }\left(\bmod ^{*} / \mathrm{low}\right) \\
\text { n }(\%)\end{array}$ & Chi $^{2}$ & P-value & OR (95\%CI); P-value & AOR (95\%CI); P-value \\
\hline \multicolumn{7}{|l|}{ Caregivers Age } \\
\hline $15-25$ & $38(46.44)$ & $44(53.66)$ & \multirow{3}{*}{3.994} & \multirow{3}{*}{0.407} & - & \\
\hline $26-35$ & $83(51.55)$ & $78(48.45)$ & & & $0.66(0.37-1.17)$ & \\
\hline $46-65$ & $22(38.60)$ & $35(61.40)$ & & & $1.52(0.87-2.64)$ & \\
\hline \multicolumn{7}{|l|}{ Caregiver type } \\
\hline Non-biological mothers & $6(54.55)$ & $5(45.45)$ & \multirow{2}{*}{0.583} & \multirow{2}{*}{0.747} & $1.43(0.37-5.52)$ & \\
\hline Marital status & & & & & & \\
\hline Married & $131(48.34)$ & $140(51.66)$ & \multirow{2}{*}{1.102} & \multirow{3}{*}{0.576} & - & \\
\hline Not married & $12(41.38)$ & $17(58.62)$ & & & $1.75(0.72-4.25)$ & \\
\hline Occupation & & & & & & \\
\hline Formal & $1(7.69)$ & $12(92.31)$ & \multirow{2}{*}{8.713} & \multirow{2}{*}{0.013} & - & - \\
\hline $\begin{array}{l}\text { Informal } \\
\text { Educational status }\end{array}$ & $142(49.48)$ & $145(50.52)$ & & & $0.15(0.02-1.16) ; 0.066$ & $0.18(0.02-1.47) ; 0.072$ \\
\hline Educated & $62(43.66)$ & $80(56.34)$ & \multirow{2}{*}{7.284} & \multirow{2}{*}{0.026} & - & - \\
\hline $\begin{array}{l}\text { Not educated } \\
\text { Religion }\end{array}$ & $81(51.27)$ & $77(48.73)$ & & & $0.61(0.38-0.99) ; 0.041$ & 0.68 (0.41- 1.10); 0.068 \\
\hline Christians & $116(50.00)$ & $116(50.00)$ & \multirow{3}{*}{4.648} & \multirow{3}{*}{0.098} & - & \\
\hline Non-Christians & $27(39.71)$ & $41(60.29)$ & & & $1.63(0.90-2.98)$ & \\
\hline Tribe & & & & & & \\
\hline Dagaabas & $141(48.79)$ & $148(51.21)$ & \multirow{2}{*}{4.020} & \multirow{2}{*}{0.134} & - & \\
\hline Others & $2(18.18)$ & $9(81.82)$ & & & $5.54(0.70-43.87)$ & \\
\hline
\end{tabular}

*moderate

\subsection{Associations Between the Background Characteristics and Caregivers Attitude Towards GMP Activities}

The result showed a significant associations between caregivers attitude towards GMP and type of caregiver $(p=.021)$, marital status $(p=.009)$ and occupation $(p=.014)$. To further explore the strength of associations, multiple logistic regression analysis was used to confirm associations between attitudes towards GMP and the independent variables. The analyses confirm the associations between attitude towards 
GMP and caregiver type, marital status and occupation. The associations also indicated that non-biological mothers were $74.0 \%$ less likely to be associated with good attitude towards GMP than those who are biological mothers; also unmarried caregivers were $64.0 \%$ less likely, and informal occupation were 3.8 times more likely to be associated with good attitude towards GMP than those married. Moreover, when variables that were having associations with good attitudes towards GMP from bivariate analysis were alone explored for strength of associations, it was revealed that type of caregiver have no associations with good attitudes towards GMP. However, marital status and occupation were having significant associations with good attitude towards GMP; unmarried caregivers and those with informal occupation were $60.0 \%$ less likely and 4.4 times more likely to be associated with good attitudes in GMP than those married (Table 9).

Table 9. Associations between the background characteristics and caregivers attitude towards GMP.

\begin{tabular}{|c|c|c|c|c|c|c|}
\hline \multirow[b]{2}{*}{$\begin{array}{l}\text { Background } \\
\text { Characteristics }\end{array}$} & \multicolumn{2}{|c|}{ Attitude towards GMP } & \multicolumn{2}{|c|}{ Pearson chi square } & \multicolumn{2}{|c|}{ Odd ratio/Confidence Interval } \\
\hline & $\begin{array}{l}\text { Good (high) n } \\
(\%)\end{array}$ & $\begin{array}{l}\text { Poor }\left(\bmod ^{*} / \mathrm{low}\right) \mathrm{n} \\
(\%)\end{array}$ & $\mathrm{Chi}^{2}$ & P-value & OR (95\%CI); P-value & AOR (95\%CI); P-value \\
\hline \multicolumn{7}{|l|}{ Caregivers Age } \\
\hline $15-25$ & $2(2.44)$ & $80(97.56)$ & & & - & \\
\hline $26-35$ & $4(2.48)$ & $154(97.52)$ & 3.995 & 0.136 & $1.80(0.99-3.29)$ & \\
\hline $46-65$ & $1(1.75)$ & $56(98.25)$ & & & $0.19(0.57-2.50)$ & \\
\hline \multicolumn{7}{|l|}{ Caregiver type } \\
\hline Non-biological mothers & $0(0.00)$ & $11(100.00)$ & 5.310 & 0.021 & $0.26(0.08-0.88) ; 0.039$ & $0.36(0.10-1.31) ; 0.079$ \\
\hline \multicolumn{7}{|l|}{ Marital status } \\
\hline Married & $7(2.58)$ & $264(97.42)$ & 6731 & 0000 & - & - \\
\hline \multicolumn{7}{|l|}{ Occupation } \\
\hline Formal & $2(15.38)$ & $11(84.62)$ & 6031 & 0014 & - & - \\
\hline $\begin{array}{l}\text { Informal } \\
\text { Educational status }\end{array}$ & $5(1.74)$ & $282(98.26)$ & 0.031 & 0.014 & $3.76(1.22-11.56) ; 0.027$ & $4.41(1.42-13.68) ; 0.031$ \\
\hline $\begin{array}{l}\text { Not educated } \\
\text { Religion }\end{array}$ & $3(1.90)$ & $155(98.10)$ & 0.440 & 0.504 & $1.19(0.71-2.02)$ & \\
\hline Christians & $6(2.59)$ & $226(97.41)$ & 0406 & 0524 & - & \\
\hline Non-Christians & $1(1.47)$ & $67(98.53)$ & 0.406 & 0.524 & $1.23(0.65-2.35)$ & \\
\hline Tribe & & & & & & \\
\hline Dagaabas & $7(2.42)$ & $282(97.58)$ & 2548 & 0110 & - & \\
\hline Others & $0(0.00)$ & $11(100.00)$ & 2.548 & 0.110 & $0.38(0.11-1.29)$ & \\
\hline
\end{tabular}

\subsection{Associations Between the Background Characteristics and Caregivers Practices on GMP}

The results revealed a significant associations between practices in GMP and type of caregivers $(p=.019)$ and tribe of caregivers' $(p=.019)$. To further test the strength of associations a multiple logistic regression was done to confirm the association between practice in GMP and the explanatory variables, the analysis did not confirm any associations. However, the logistic regression analysis omitted the type of caregivers' and caregivers' tribe due to the fact that biological mothers and Dagaabas predicts success perfectly, their observation were not used (Table 10).

Table 10. Associations between the background characteristics and practices of caregivers'.

\begin{tabular}{|c|c|c|c|c|c|}
\hline \multirow{2}{*}{ Background Characteristics } & \multicolumn{2}{|c|}{ Attitude towards GMP } & \multicolumn{2}{|c|}{ Pearson chi square } & \multirow{2}{*}{$\begin{array}{l}\text { Odd ratio/Confidence Interval } \\
\text { OR }(95 \% \text { CI }) ; \text { P-value }\end{array}$} \\
\hline & Good (high) n (\%) & Poor (mod $/$ low) n (\%) & $\mathrm{Chi}^{2}$ & P-value & \\
\hline \multicolumn{6}{|l|}{ Caregivers Age } \\
\hline $15-25$ & $61(74.39)$ & $21(25.61)$ & & & - \\
\hline $26-35$ & $119(73.91)$ & $42(26.09)$ & 1.278 & 0.528 & $1.12(0.63-1.98)$ \\
\hline $46-65$ & $46(80.70)$ & $11(19.30)$ & & & $0.78(0.39-1.58)$ \\
\hline \multicolumn{6}{|l|}{ Caregiver type } \\
\hline Biological Mothers & $221(76.47)$ & $68(23.53)$ & & 0010 & \\
\hline \multicolumn{6}{|l|}{ Marital status } \\
\hline Married & $205(75.65)$ & $66(24.35)$ & & & - \\
\hline Not married & $21(72.41)$ & $8(27.59)$ & 3.473 & 0.062 & $2.51(0.93-6.79)$ \\
\hline \multicolumn{6}{|l|}{ Occupation } \\
\hline Formal & $7(53.85)$ & $6(46.15)$ & 3853 & 0050 & - \\
\hline Informal & $219(76.31)$ & $68(23.69)$ & 3.853 & 0.050 & $0.16(0.02-1.27)$ \\
\hline \multicolumn{6}{|l|}{ Educational status } \\
\hline Not educated & $127(80.38)$ & $31(19.62)$ & 3.317 & 0.009 & $0.63(0.39-1.04)$ \\
\hline
\end{tabular}




\begin{tabular}{|c|c|c|c|c|c|}
\hline \multirow{2}{*}{ Background Characteristics } & \multicolumn{2}{|c|}{ Attitude towards GMP } & \multicolumn{2}{|c|}{ Pearson chi square } & \multirow{2}{*}{$\begin{array}{l}\text { Odd ratio/Confidence Interval } \\
\text { OR }(95 \% \mathrm{CI}) ; \text { P-value }\end{array}$} \\
\hline & Good (high) n (\%) & Poor (mod*/low) n (\%) & $\mathrm{Chi}^{2}$ & P-value & \\
\hline \multicolumn{6}{|l|}{ Religion } \\
\hline Christians & $174(75.00)$ & $58(25.00)$ & 0053 & 0817 & \\
\hline $\begin{array}{l}\text { Non-Christians } \\
\text { Tribe }\end{array}$ & $52(76.47)$ & $16(23.53)$ & 0.053 & 0.817 & $0.93(0.53-1.66)$ \\
\hline Dagaabas & $219(75.78)$ & $70(24.22)$ & & & Omitted** \\
\hline Others & $7(63.64)$ & $4(36.36)$ & 5.540 & 0.019 & \\
\hline
\end{tabular}

** Omitted: Statistical analysis excluded caregiver type and tribe variables in the logistic regression model

\section{Discussion}

This study revealed that $96.3 \%$ of the caregivers were biological mothers of the children. This conforms with a study conducted by Gyampoh [7] which stated $95 \%$ as biological mothers for children involved in the study, not surprise because in the Ghanaian culture women are known to be the primary caregivers' for children. About $52.6 \%$ of the caregivers' had never been to school similar to what was found in Upper West region $(54.0 \%)$ by [11]. This study found $90.3 \%$ of the caregivers' married; the finding is higher than a similar study conducted in Accra by [7]. The result revealed $75.7 \%$ of the caregivers' were married; the difference may be due to the fact that this present study was done in a peri-urban setting while that of [7] was conducted in the urban setting. Also in this study, 58.3\% of the caregivers' were farmers, this is slightly higher in comparison to [11] survey result of $52.0 \%$ women who were in agriculture in the Upper West Region. The mean age of caregivers' in the study was 29 years which is almost the same as 28years with [7] study.

This study shows that about $53.0 \%$ of the caregivers have good (high) knowledge in child's growth monitoring and promotion. However, $91.7 \%$ of the caregivers' in this present study have knowledge on the importance of GMP, this findings is consistent to the study of [12] who also discovered that $92 \%$ of the caregivers' were having knowledge on the importance of GMP. Knowledge on recommended feeding practices among caregivers was found to be above $80.0 \%$ with the exception of frequency of feeds among children between 12-23months, the result differs from a descriptive qualitative studies conducted by [12\&6] in rural Zambia and Ethiopia who found out that knowledge on feeding practices was poor. This differences may be due to the study design used the studies, the present study used quantitative methods while others studies applied qualitative methods. Furthermore, in this study, $78.7 \%$ of the caregivers' had good knowledge on the purpose of growth chart, on the other hand, as high as $81.5 \%$ of the caregivers' were not able to interpret the growth curves. This is similar to other findings from study conducted by [13] where more than half of the caregivers' were unable to interpret the growth curves. The low comprehension on the curves may be that, health professionals were not using the child growth charts as an education tool [7]. This implies that these caregivers' would not be able to identify a child with growth faltering and when to take action to prevent malnutrition and it related consequences.
This study recorded $98.0 \%$ of caregivers' having good (high) attitudes in GMP in general. Contrary to findings from a study by [14], the study discovered that caregivers had poor participation in growth monitoring and promotion. Nevertheless, the findings were similar to the findings of a study conducted by [15] which found out that mothers in growth monitoring program have good preventive behaviour. In this study, it also revealed that cultural beliefs and social pressure do not have any influence on mothers ability to practice exclusive breastfeeding and complementary in contrast to what was concluded by [16] on barriers in practicing exclusive breastfeeding among peri-urban mothers from Manya and Yilo Krobo in Eastern Region of Ghana. In [7] study through review of records found out that $75 \%$ of caregivers' attended growth monitoring regularly, however this study shows that about $93.7 \%$ of caregivers' were attending GMP session, probably this is because this study focused on perception of caregivers' and not records. Growth monitoring and promotion has been a platform where other preventive activities are linked with to improve child health in the community [1]. This study revealed that, caregivers' perceived preferred activities of most important were weighing, immunization and treatment as $67.0 \%, 67.0 \%$ and $67.0 \%$ respectively; this might be so because of the perceived benefits that was reported in the qualitative study among mothers on the benefits and challenges in growth monitoring [6].

This study shows that $70.0 \%$ of the caregivers' have good (high) practice in GMP in general. Exclusive breastfeeding is a recommended feeding practice to improve optimal growth in children. In this present study about $88.0 \%$ of the caregivers' were practicing exclusive breastfeeding. This is higher than findings from other studies conducted by $[17,12$ $\& 11]$ as $55 \%, 52.3 \%$ and $28.9 \%$ respectively. The good practice among caregivers' may be due to current interventions such as community- infant and young child feeding practices being implemented in the study area. Comparatively caregivers' with children between 6-23months that gave diverse diet was higher $(52.0 \%)$ in this study than what was reported by $\left[\begin{array}{l}7 \\ \&\end{array} 11\right]$ as $43.6 \%$ and $13.0 \%$ respectively. Hand washing has been an effective way of preventing communicable diseases such as diarrhoea, hence washing hands at particular times among caregivers will prevent frequent infection [18]. Yet in this study as high as $27.1 \%$ and 32.1 of the caregivers' failed to wash their hands after visiting the toilet and before cooking. Besides, $63.9 \%$ of the caregivers' children slept in an insecticide treated bed net the previous night. This finding is higher than what was 
discovered in a study conducted by [12] to assess knowledge, attitude and practices of child survival interventions among mothers in rural Zambia, the study revealed that only $10.0 \%$ used bed nets. The difference may be because of the current intervention of free ITN distribution in Ghana, among pregnant women and children under 5years to prevent malaria.

Only $16.2 \%$ of the children recorded growth faltering in this study. More $(84.4 \%)$ of the caregivers' children between 12-23months had faltered in growth than those below 11 months in this study; contrary to other findings from studies conducted by [19\&20] to assess timing of growth faltering in children, the results revealed that it peaks between 3 and 12 months, the reason for the difference could be that while their study was to determine the beginning of growth faltering, this present study focus on distribution. Appropriate documentation including weight recording, plotting and growth curved interpretation is important tool to help improve child health and growth [1\&21]. However, in this study about $34.0 \%$ of the children weights were not documented in their growth charts. This is lower than what was also observed in the study in Accra metropolis by [7] as $54.4 \%$ of children weight recorded were not joined together. This has serious implications on the child health status, since the caregivers' and service providers cannot tell if the child growth is normal or abnormal for action.

On the other hand, children who had their growth faltering, only $5.6 \%$ were referred for further screening and treatment but none of the caregivers' with children whose growth faltered received follow up visit, whereas the rest of the caregivers were encourage to improve on child care practices. Conversely, in a systemic review study conducted by [2] to evaluate the effect of routine growth monitoring on children and their health and mothers' knowledge in nutrition revealed that in order to address the causes of growth faltering, it is important to follow actions such as referral for medical treatment and follow-up visits to caregivers' with such children.

In this study, educated caregivers' were found to have knowledge in GMP. A significant association was observed with ( $p=.026)$ among caregivers. However, other study conducted by [7] in Accra metropolis among caregivers' with children between 0-23 months showed that caregivers' with regular attendance had good knowledge in GMP, though the association was found not to be significant. Additionally, occupation $(p=.013)$ of caregivers' were found to have associations with knowledge. This result indicates that caregivers' with the informal sector occupation were $85 \%$ less likely to be associated with good knowledge in GMP.

Again, this study found out that caregivers' type $(p=.021)$ was significantly associated with attitudes in GMP in agreement with a study on mothers attitudes and child weight, feeding practices as well as growth monitoring as a preventive activity for malnutrition in Myanmar which showed that mothers had positive perception toward child feeding practices [15]. However, a cross-sectional study conducted by [22] in Ga West Municipality in Greater Accra
Region of Ghana to compare the effects of community-based growth promotion and GMP program on caregivers' IYCF knowledge and practices found marital status with significant association $(p=.007)$ with practices while this present study found marital status to be associated $(p=.009)$ with attitude.

Educational status of a mother was found to be significantly associated with child care practices in a study conducted by [23] to assess knowledge and practices among mothers on IYCF practices and in a similar study among 720 mothers in Uganda by [24], while in this study education was found not to be associated with practices in GMP. However, the study revealed occupation $(\mathrm{p}=0.019)$ and caregivers tribe $(p=0.019)$ as significantly associated with good practice in GMP.

\section{Study Limitation(s)}

Knowledge, Attitudes and Practices questions contains few open-ended questions; this may not provide clear and indepth information as required. On the other hand, other questions used were not also exhaustive due to the study design and limited time. The study design only provides a snap shot of the outcome at a point in time which may not be the actual representation of situation in GMP.

\section{Conclusion}

Generally, high prevalence of knowledge, attitudes and practices were recorded on GMP among caregivers. Those with no education and informal occupation were less likely to be associated with good knowledge; also non biological mothers and unmarried were less likely to be associated with good attitudes. Despite the achievement in the coverage of GMP, implementation of C-IYCF program and information, education and communication activities in district, the findings on GMP outcome is not satisfactorily.

\section{Recommendations}

In order to achieve the effectiveness and full benefits of GMP to improve child health and nutrition for better physical growth and development. It is important that different approaches be used to improve the GMP activities. The following are recommended:

The District Health Management Team should intensify activities on community-infant and young child feeding practices

District Health Management Team should strengthen the growth monitoring and promotion system by addressing poor recording in growth charts and improve caregivers' knowledge on growth curves.

District Health Management Team should focus on the strategies and content of health education messages to caregivers'

District Health Management Team should strengthen home visits activities in the district.

Ghana Health Service should design, develop and implement a tool to identify children with growth faltering.

Ghana Health Service should re-strategize on home 
visiting policy designs for community health workers

Ghana Health Service in collaboration with the communities should review and strengthen child growth monitoring and promotion services as a top priority for public health and nutrition action

Further studies should be conducted on effects of maternal comprehension of growth curves on infant growth pattern.

Other studies should be conducted to explore health staff knowledge and practices on the concepts and principles in growth monitoring and promotion.

\section{Acknowledgement}

The authors wish to acknowledge Dr. Sebastien Sandaare (The District Director of Health Service, Lawra) for providing the list of all mothers who have registered and are attending child welfare clinic at various sites. We also want to express our sincere gratitude to the mothers for providing us with all the necessary information needed for the study.

\section{References}

[1] Griffiths, M., \& Del Rosso, J. (2007). Growth Monitoring and the Promotion of Healthy Young Child Growth. Retrieved from http://www.manoffgroup.com/documents/GMP_UNICEF_No v_1608.pdf

[2] Panpanich, R., \& Garner, P. (1999a). Growth monitoring in children. The Cochrane Library. Retrieved from http://onlinelibrary.wiley.com/doi/10.1002/14651858.CD0014 43/full

[3] Griffiths, M., Dickin, K., \& Favin, M. (1996). Promoting the Growth of Children: What Works (Wold Bank Nutrition Toolkits). The World Bank.

[4] UNICEF. (n.d.). Growth Monitoring and Promotion: Intervention or Platform for Action? Presented at the 35th SCN Session WG Breastfeeding and Complementary Feeding. Retrieved from http://www.unsystem.org/SCN/Publications/AnnualMeeting/S CN35/wgbfcf/Nune\%20MANGASARYAN.pdf

[5] Ashworth, A., Shrimpton, R., \& Jamil, K. (2008). Growth monitoring and promotion: review of evidence of impact. Maternal \& Child Nutrition, 4 (s1), 86-117.

[6] Bilal, S. M., Moser, A., Blanco, R., Spigt, M., \& Dinant, G. J. (2014). Practices and Challenges of Growth Monitoring and Promotion in Ethiopia: A Qualitative Study. Journal of Health, Population, and Nutrition, 32 (3), 441.

[7] Gyampoh, S. (2012). Assessment of Clinic-Based Growth Monitoring and Promotion in the Accra Metropolitan Area of Ghana. University of Ghana. Retrieved from http://ugspace.ug.edu.gh/handle/123456789/5418

[8] Lawra District Health Directorate Report. (2014). ANNUAL PERFORMANCE REPORT. Lawra, Upper West Region, Ghana: Ghana Health Service 。

[9] Charlton, K. E., Kawana, B. M., \& Hendricks, M. K. (2009). An assessment of the effectiveness of growth monitoring and promotion practices in the Lusaka district of Zambia. Nutrition, 25 (10), 1035-1046。
[10] George W. Snedecor and William G. Cochran. (1989). Statistical Methods, 8th Edition; Iowa State University Press. Xix +491 pp.

[11] Ghana DHS 2014 - KIR - 6 April 2015.pdf. (n.d.).

[12] Banda, D. H. (2012). Incorporation of child survival strategies among mothers in Zambia: a knowledge, attitude and practice survey. Retrieved from http://dspace.unza.zm:8080/jspui/handle/123456789/1521

[13] Roberfroid, D., Pelto, G. H., \& Kolsteren, P. (2007). Plot and see! Maternal comprehension of growth charts worldwide: Maternal comprehension of growth charts worldwide. Tropical Medicine \& International Health, 12 (9), 1074-1086. http://doi.org/10.1111/j.1365-3156.2007.01890.x

[14] Roberfroid, D., Kolsteren, P., Hoeree, T., \& Maire, B. (2005). Do growth monitoring and promotion programs answer the performance criteria of a screening program? A critical analysis based on a systematic review. Tropical Medicine \& International Health, 10 (11), 1121-1133.

[15] Chit, T.-M., Kyi, H., \& Thwin, A. (2003). Mothers' beliefs and attitudes towards child weight, child feeding and related practices in Myanmar. Nutrition and Health, 17 (3), 231-254.

[16] Otoo, G. E., Lartey, A. A., \& Pérez-Escamilla, R. (2009). Perceived incentives and barriers to exclusive breastfeeding among periurban Ghanaian women. Journal of Human Lactation, 25 (1), 34-41.

[17] Tharmer, K. Y. A. H. (2007). Mothers' knowledge and attitude regarding childhood survival. Retrieved from http://www.mejfm.com/journal/Jan2007/mother-child.htm

[18] Mwangi, J. (2012). Preliminary findings from the 2011 National MICs to the Health Summit: is Ghana reducing disparities and improving equity on key health outcomes. Ghana Annual Health Summit, 20-22.

[19] Shrimpton, R., Victora, C. G., de Onis, M., Lima, R. C., Blössner, M., \& Clugston, G. (2001). Worldwide timing of growth faltering: implications for nutritional interventions. Pediatrics, 107 (5), e 75-e75.

[20] Maleta, K. (2003). Timing of growth faltering in rural Malawi. Archives of Disease in Childhood, 88 (7), 574-578. http://doi.org/10.1136/adc.88.7.574

[21] Magalemele, H. M. (2014). Experiences of child health nurses managing malnourished children in the growth monitoring and promotion service in region $D$, Gauteng province. Retrieved from http://146.141.12.21/handle/10539/14307

[22] Agbozo, F., Colecraft, E., \& Ellahi, B. (2015). Impact of type of child growth intervention program on caregivers' child feeding knowledge and practices: a comparative study in Ga West Municipality, Ghana. Food Science \& Nutrition. Retrieved from http://onlinelibrary.wiley.com/doi/10.1002/fsn3.318/full

[23] Memon, S., Shaikh, S., Kousar, T., Memon, Y., \& others. (2010). Assessment of infant feeding practices at a tertiary care hospital. JPMA. The Journal of the Pakistan Medical Association, 60 (12), 1010-1015.

[24] Wamani, H., Astrøm, A. N., Peterson, S., Tylleskär, T., \& Tumwine, J. K. (2005). Infant and young child feeding in western Uganda: knowledge, practices and socio-economic correlates. Journal of Tropical Pediatrics, 51 (6), 356-361. http://doi.org/10.1093/tropej/fmi048 